\title{
Effect of Breakfast Eating Patterns and Anthropometric Measurements on Cognitive Function of Early Adolescents in Rural Area of Sidama Zone, Southern Ethiopia
}

\author{
Anchamo Anato Adole ${ }^{1, *}$, Pragya Singh², Tafese Bosha ${ }^{1}$, Beruk Berhanu Desalegn ${ }^{1}$ \\ ${ }^{1}$ School of Nutrition, Food Science and Technology, Hawassa University, Hawassa, Ethiopia \\ ${ }^{2}$ Department of Public Health \& Primary Care, College of Medicine, Nursing \& Health Sciences, Fiji National Universityty, Suva, Fiji \\ Email address: \\ anchamoanato@yahoo.com (A. A. Adole), pragyasingh85@yahoo.co.in (P. Singh), tafese.bosha@gmail.com (T. Bosha), \\ berhanuberuk@gmail.com (B. B. Desalegn)
}

\section{To cite this article:}

Anchamo Anato Adole, Pragya Singh, Tafese Bosha, Beruk Berhanu Desalegn. Effect of Breakfast Eating Patterns and Anthropometric Measurements on Cognitive Function of Early Adolescents in Rural Area of Sidama Zone, Southern Ethiopia. Journal of Food and Nutrition Sciences. Vol. 3, No. 6, 2015, pp. 251-258. doi: 10.11648/j.jfns.20150306.19

\begin{abstract}
Background: Poor growth and breakfast eating patterns are associated with delayed mental development and that there is a relationship between impaired growth status and both poor performance and reduced intellectual achievements. The objective of this study was to assess the effects of breakfast eating patterns and anthropometric measurements on cognitive function among early adolescents in the Rural Sidama, Southern Ethiopia. A cross-sectional study was conducted from June to July 2012. Structured questionnaire was used to capture breakfast eating patterns, socio-economic and demographic factors. Anthropometric status was measured using the UNICEF SECA weighing scale and shorr measuring board. Kaufman Assessment Battery for Children-II tests was used for cognitive function measurement. A representative sample size of 211 participants was selected randomly from 4 kebeles. The data was analyzed with SPSS version 16.0 software and WHO anthroplus version 1.04. Results: Of the 208 interviewed, $52 \%$ were girls while $48 \%$ were boys with mean $( \pm \mathrm{SD})$ age of $12.01 \pm 0.82$ years. Breakfast skipping prevalence was $42.3 \%$. Breakfast eating patterns and height-for-age $\mathrm{Z}$ score were significant predictors of Pattern Reasoning cognitive test scores $(\mathrm{P}<0.001)$. Body mass index for age $\mathrm{Z}$ score was a significant predictor $(\mathrm{P}<0.001)$ of a combined Simultaneous scale. Regular breakfast pattern, height for age and body mass index for age $\mathrm{Z}$ score were significantly $(\mathrm{P}<0.001)$ associated with Pattern Reasoning explaining 28.8\% variation. Conclusion: Adolescents who were stunted and underweight had lower cognitive test scores compared to those who were normal as well as those who consume breakfast irregularly. Anthropometric status and breakfast eating patterns was significant predictor of cognitive function of adolescents in the study area. We recommended that, parents and adolescents should be educated and trained on healthy breakfast eating patterns and good nutrition practices for healthy cognitive development.
\end{abstract}

Keywords: Breakfast, Anthropometric Measurements, Cognitive Function, Adolescents, Southern Ethiopia

\section{Introduction}

Breakfast eaters of all ages tend to have a healthier diet. Children and adolescents need to meet nutrient requirements to maintain an appropriate growth rate while avoiding nutrient deficiencies which can lead to poor health [1]. Those who skipped breakfast consumed fewer calories throughout the day than children who ate breakfast, demonstrating that children do not compensate nutritionally later in the day for the energy skipped at breakfast [2]. Accordingly, breakfast skippers also had lower intakes of fat, carbohydrate, and protein [2]. Breakfast is seen as an important first source of energy for the day, so that the brain can cope with the demands of the morning [3]. Children and adolescents seem to be most likely to skip breakfast [4]. While skipping breakfast induces short term metabolic changes, it may also affect overall nutritional status [5]. The effect of breakfast on cognitive performance may be by providing essential nutrients to the brain as well as alleviating hunger. A lack of energy leads to decreased glucose and insulin levels in the body associated with impaired cognitive performance. If such a lack of energy provision to the brain occurs frequently, it may be reflected in the level of school performance in the long run [5].

Eating breakfast provides energy for the brain and improves 
learning. The effect of glucose deprivation is noticeable by a fall in blood glucose level of sufficient degree, which is rapidly followed by disturbance in cerebral function. The gap of about 10 to 12 hours between dinner and breakfast causes, low blood glucose levels and habitually missing breakfast can adversely affect cognitive performance [6]. The gradual decline of insulin and glucose level could determine a stress response, which interferes with different aspects of cognitive function, such as attention and working memory. It is plausible that the decline in cerebral iron level likely to result from diet that is deficient in heme intensifies the stress associated with overnight and morning fast [6]. Sustained contribution of breakfast to a person's health status over time is particularly relevant for children whose daily dietary intake barely meets the requirements [7]. Breakfast eaters tend to have higher basal metabolism, and have less craving for the food. Children who skip breakfast but eat later on in the day may catch up their daily nutrient requirements but are unlikely to attend and concentrate on the teacher's lecture in the morning session because they are hungry. If the transitory metabolic changes due to skipping breakfast were to occur frequently, they would be likely to have a cumulative adverse effect that may place a child's school progress at risk [5].

Laboratory study showed that missing breakfast detrimentally affects children's cognition and that undernourished children are more likely to be affected [8]. Other studies have explored the relationship between nutritional, anthropometric indicators and school achievement indicators as grade level, age at enrollment, absenteeism, achievement test scores, IQ, and performance on selected cognitive tasks including concentration in the classroom. According to review by [9] on nine studies, nutritional status was significantly associated with cognitive test scores or school performance indicators. Consistently, past and present nutritional status (as captured by height-for-age and weight-for-height respectively) were linked to higher cognitive test scores [10].

Taller children were also likely to be enrolled in school earlier than shorter ones. In China, height-for-age was also a predictor of the degree to which a child's grade level was age-appropriate. One standard deviation improvement in height represented an increment of 0.3 years less far behind in terms of school grade-for-age [10]. According to [9] study in Kenya showed, children who were better nourished had higher composite scores on a test of verbal comprehension and the Raven Progressive Matrices. Furthermore, better nourished girls were more attentive during classroom observations than their malnourished female counterparts. For the children as a group, the best predictors of cognitive scores were duration of schooling, food intake (current nutrition), physical stature (nutritional history), and socioeconomic status. Regardless of the social and economic resources of the family, children who had more adequate diets scored higher on the cognitive battery than those with less adequate intake [9]. Similarly, [11] concluded from her study in the Philippines that, the academic performance and mental ability of children with good nutritional status were significantly higher than that of children with poor nutritional status, as a whole, even when family income, school quality, teacher ability, or mental ability were controlled. Although the relationship between health and nutritional status on one hand and academic achievement on the other varied by grade level and subject matter, a significant positive relationship was found linking nutritional status to mental ability and academic achievement. Therefore, the purpose of this study was to assess the effects of breakfast eating patterns and anthropometric measurements on cognitive function among early adolescents in Rural Sidama, Southern Ethiopia.

\section{Materials and Methods}

The study was conducted in Shebedino District, Sidama Zone, in Southern Ethiopia from June to July 2012. The District is located at 1500 to 3000 altitude above sea level and $6^{\circ} 46^{\prime}$ and $7^{\circ} 45^{\prime}$ latitude North and $39^{\circ}$ and $40^{\circ}$ longitude East with annual average temperature $16^{\circ} \mathrm{C}-25^{\circ} \mathrm{C}$ and annual rainfall $800-1600 \mathrm{~mm}$. It is one of the 19 Districts in Sidama Administrative Zone. The District has 32 rural and 3 urban Kebeles. The total population of the District was estimated to be 232, 964. The economic activities of the District are agriculture mainly focusing on coffee, maize, barley, teff, enset, sugarcane, and khat production and rearing of animals, and trade. A cross-sectional study design was employed to assess the effects of breakfast eating patterns, anthropometric measurements on cognitive function in early adolescents.

This age group was purposively selected because they characterized by the onset of puberty and increased cognitive development as well as their brain needs more nutrients than the brains of older adolescents [12]. Besides, adolescents have high nutritional need, due to brain development processes and physical growth, while at the same time they have the highest rate of breakfast skipping among school-aged children [13 and 14]. The total sample size was 211 which was calculated using $\mathrm{G}^{*}$ power version 3.1.3 [15]. The study employed two stage cluster sampling technique. Initially all kebeles (Smallest unit of administrative unit) were listed and of these, four were randomly selected. Probability Proportional to Size (PPS) sampling technique was employed so as to get representative adolescents sample size from each four kebele clusters. Individuals were randomly selected by following procedure: walking to the center of selected kebeles, a direction was chosen randomly by spinning a pencil on the ground and the direction was noted when stopped. The number of households was counted along this line by walking in the direction from center to the outer perimeter. A random number table was used to obtain a number between one and the number of households counted. By walking to the selected household, the adolescents were examined along the randomly chosen line. Then, the next nearest house was visited until the last was surveyed in the randomly chosen line. The same procedure was repeated until enough samples from the kebele were collected [16].

Data Collection

Training was provided for data collectors and supervisor. 
Pre-test was done on $10 \%$ of the sample size and these subjects were excluded from the original samples. Principal investigator did three cognitive tests with the help of two medical students and one undergraduate student.

Demographic characteristics and socioeconomic status were assessed using questions adapted from the Ethiopia Demographic and Health Survey 2012 report [17]. Food consumption patterns of respondents were assessed using a standardized food frequency questionnaire [18].

Body weight was recorded to the nearest $0.1 \mathrm{~kg}$ using the UNICEF SECA weighing scale. Height was measured to the nearest $0.1 \mathrm{~cm}$ using the shorr measuring board without shoe in standing position. Stunting was defined as HAZ scores less than -2SD and normal was defined as HAZ greater than or equal to -2SD. Underweight was defined as BAZ scores less than $-2 \mathrm{SD}$ and normal was defined as $\mathrm{BAZ}$ greater than or equal to -2SD [19].

The Kaufman Assessments Battery (KABC-II) was used to assess adolescents' cognitive function which is made up of a series of tests which measure Sequential processing, Simultaneous processing and planning ability [20]. From the tests which measure Sequential processing (short term memory), Number Recall, Word Order and Hand Movement were used. For measuring Simultaneous processing, the Rover and Triangles were used and Planning (fluid reasoning) was measured by using Pattern.

Data were analyzed using descriptive and analytical statistical measures. A univariate analysis was conducted to obtain summary statistics (frequencies, percentage, means and standard deviations) of the variables investigated. Backward multiple linear regression was done to assess the contribution of each independent variable (socioeconomic status, type of breakfast eating patterns, mother's education and occupation, sex of study participants, age, occupation and education of father) in explaining the variation in the dependent variables (Sequential scale, Simultaneous scale and Pattern Reasoning). Independent sample t-test was used to compare cognitive test scores across anthropometric status and breakfast eating patterns.

Analyses of data were performed with SPSS version 16.0 and WHO anthroplus version 1.04.

Ethical clearance was obtained from the Institutional Review Committee of Hawassa University. Permission was obtained from Shebedino District Administration and written consents were obtained from adolescents and their parents or caregiver.

\section{The Study Results}

\subsection{Breakfast Eating Patterns and Anthropometric Status of Study Participants}

With regard to breakfast eating patterns, $57.7 \%$ of adolescents regularly consumed breakfast, $42.3 \%$ consumed it irregularly (skipping 2 or 3 times per week).

The reasons for skipping breakfast are presented in Figure 1. About $9 \%$ of study participants indicated that they did not like what was available to eat and $11.1 \%$ indicated that they had nothing to eat at home.

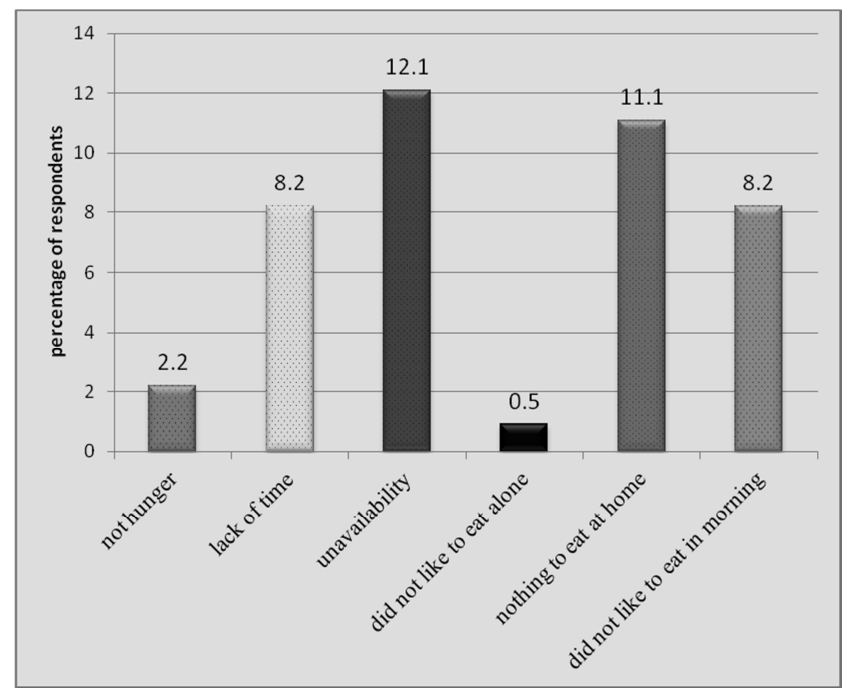

Figure 1. The reasons for study participants to skip breakfast in Rural Area of Sothern Ethiopia.

Anthropometric measurements result is presented in table 1 . Thirteen percent of study participants were underweight (BMI-for-age $<-2 \mathrm{SD}$ ) and $10.1 \%$ were stunted (Height-for-age $<-2 \mathrm{SD})$. The mean BMI-for-age and height-for-age $\mathrm{z}$ scores were $-0.13(0.34)$ and $-0.10(0.302)$ respectively.

Table 1. Anthropometric status of study participants in Rural Area of Southern Ethiopia.

\begin{tabular}{lll}
\hline & n & Percentage \\
\hline Height-for-age Z score & & \\
Stunted (<-2SD) & 21 & 10.1 \\
Normal (>=-2SD) & 187 & 89.9 \\
Total & & 100 \\
BMI-for-age Z score & & \\
Underweight (<-2SD) & 27 & 13 \\
Normal (>=-2SD) & 181 & 87 \\
Total & & 100 \\
\hline
\end{tabular}

Table 2. Cognitive test scores of study participants according to breakfast eating patterns of adolescent in Rural Area of Southern Ethiopia.

\begin{tabular}{llll}
\hline Variables & $\begin{array}{l}\text { Every day } \\
(\mathbf{n = 1 2 0})\end{array}$ & $\begin{array}{l}\text { Sometimes } \\
(\mathbf{n = 8 8})\end{array}$ & P-value $^{\mathbf{a}}$ \\
\hline Number Recall & $8.3 \pm 2.1$ & $7.6 \pm 1.9$ & $0.013^{*}$ \\
Word Order & $11.1 \pm 2.4$ & $11.1 \pm 2.8$ & 0.96 \\
Hand Movement & $7.9 \pm 2.7$ & $6.9 \pm 2.7$ & $0.006^{*}$ \\
Triangles & $11.6 \pm 3.4$ & $10.9 \pm 3.5$ & 0.15 \\
Rover & $13.4 \pm 3.8$ & $11.9 \pm 3.8$ & $0.007^{*}$ \\
Pattern Reasoning & $6.5 \pm 2.7$ & $4.0 \pm 1.9$ & $0.001^{*}$ \\
Sequential scale & $27.3 \pm 5.6$ & $25.5 \pm 5.9$ & $0.032^{*}$ \\
Simultaneous scale & $25.0 \pm 6.1$ & $22.9 \pm 6.6$ & $0.016^{*}$ \\
\hline
\end{tabular}

*Difference is significant at level 0.05 .

${ }^{\text {a }}$ Independent sample t-test 
Comparison of adolescents cognitive test scores by breakfast eating habits is presented in Table 2. Adolescents who consumed breakfast irregularly tend to have lower test scores than did adolescents who regularly consumed breakfast. It was found that there were significant differences in the cognitive test scores with regular breakfast eaters achieving the highest mean scores compared to irregular breakfast eaters $(P<0.05)$. Those adolescents who had consumed breakfast regularly achieve higher scores in Sequential and Simultaneous scale $(\mathrm{P}=0.032)$ and $(\mathrm{P}=0.016)$ respectively.

\subsection{Cognitive Test Scores with Breakfast Eating Patterns of Study Participants}

Table3 Shows different variables which were modeled with breakfast eating patterns. When breakfast eating patterns modeled with other factors, it again showed significant association with most of the tests administered. Regular breakfast patterns, sex, height for age and education of mother were significantly $(\mathrm{P}<0.001)$ associated with Sequential scale (short term memory) explaining 13.7 percent variation. Regular breakfast patterns, education of mother, height-for-age and body-mass-index-for-age $\mathrm{Z}$ score were significantly $(\mathrm{P}<0.001)$ associated with Simultaneous scale explaining 15 percent variation.

Backward multiple linear regression analysis: Independent variables $=$ Education of mother, Education of father, Occupation of father, Occupation of mother, Sex of study subject, Family size, Household head, Age, Breakfast patterns (regular, irregular), Height-for -age $Z$ score and Body-mass-index-for-age $\mathrm{Z}$ score.

Table 3. Order and set of variables associated with Sequential scale, Simultaneous scale and Pattern Reasoning test scores of adolescents in Rural Area of Southern Ethiopia.

\begin{tabular}{llll}
\hline $\begin{array}{l}\text { Dependent } \\
\text { variable }\end{array}$ & Order of variable & $\mathbf{R}^{\mathbf{2} \%}$ & F ratio \\
\hline $\begin{array}{l}\text { Sequential } \\
\text { scale }\end{array}$ & $\begin{array}{l}\text { Sex of respondent, education of } \\
\text { mother, height-for-age Z score and } \\
\text { regular breakfast pattern }\end{array}$ & 13.7 & 8.4 \\
$\begin{array}{l}\text { Mother education, regular breakfast } \\
\text { Simultaneous } \\
\text { scale }\end{array}$ & $\begin{array}{l}\text { pattern, height-for-age Z score, Body } \\
\text { Mass Index for Z score and } \\
\text { occupation of father }\end{array}$ & 15 & 10 \\
$\begin{array}{l}\text { Occupation of father, regular } \\
\text { Pattern }\end{array}$ & $\begin{array}{l}\text { breakfast pattern height-for-age Z } \\
\text { score and Body-mass-index-for-age Z }\end{array}$ & 28.8 & 21.8 \\
\hline
\end{tabular}

Comparison of adolescents cognitive test scores by anthropometric status is presented in Table 4. Adolescents who were underweight (BMI-for-age $\mathrm{Z}$ score $<-2 \mathrm{SD}$ ) tend to have lower test scores than did adolescents who were normal. The difference were significant in Triangles $(\mathrm{P}<0.001)$, Rover $(\mathrm{P}<0.001)$ and the combined Simultaneous $(\mathrm{P}<0.001)$. Stunted (HAZ $<-2 \mathrm{SD}$ ) adolescents had lower test scores than adolescents who were normal. The difference were significant in Pattern Reasoning $(\mathrm{P}=0.005)$, Triangles $(\mathrm{P}=0.008)$, Rover $(\mathrm{P}=0.009)$ and the combined Simult neous scale $(\mathrm{P}=0.006)$.

Table 4. Study participants cognitive test scores by anthropometric status in Rural Area of Southern Ethiopia.

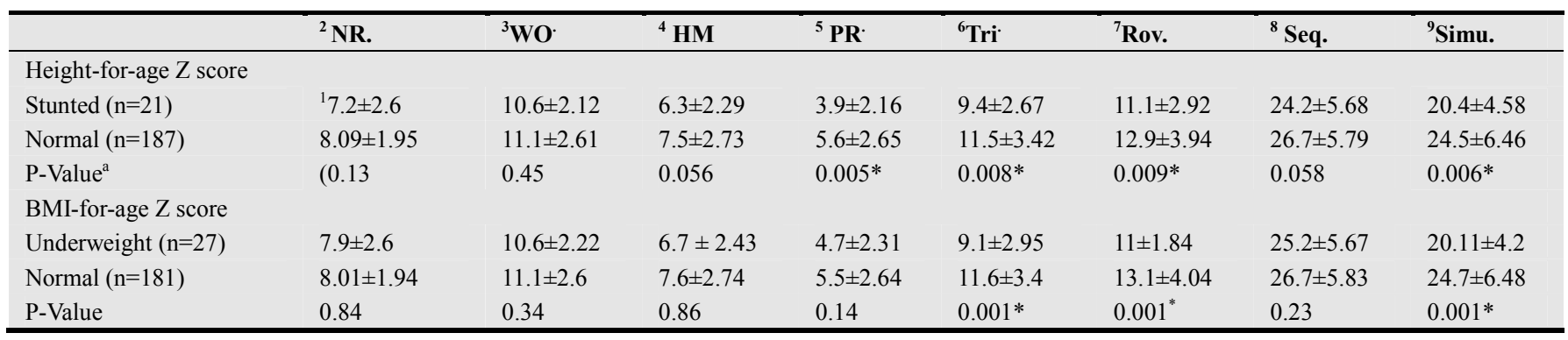

*Difference significant at 0.05 ,

${ }^{1}$ Mean \pm SD all such values, ${ }^{2}$ Number Recall, ${ }^{3}$ Word Order, ${ }^{4}$ Hand Movement, ${ }^{5}$ Pattern Reasoning, ${ }^{6}$ Triangles, ${ }^{7}$ Rover, 8 Sequential, ${ }^{9}$ Simultaneous ${ }^{\mathrm{a}}$ Independent sample t-test

\section{Discussion}

The results of the this study showed that the prevalence of breakfast skipping was high, $42.3 \%$ of the study participants were skipping breakfast 2 or 3 times per week. This is higher as compared to other countries. Study conducted in India showed that $62.3 \%$ of the adolescents habitually consumed breakfast, whereas $33.8 \%$ consumed it irregularly skipping it 2 or 3 times per week [21]. Another study done in Hong Kong showed that $30.5 \%$ of the early adolescents skip breakfast for at least one day in a week [22]. Similar study indicated that as children enter the critical growth spurt, they are even less likely to eat breakfast, with $17 \%$ of 12 and 13 year olds responding they rarely consume breakfast. As reported that $19 \%$ of American and $12 \%$ of Australian adolescents consumed breakfast irregularly, respectively [23]. Similarly, study done in Japan showed that over $15 \%$ of school age children do not eat breakfast regularly [24]. A National Child Hunger Survey of Canada reported that $42 \%$ of school age children do not regularly consume breakfast [25].

With regard to reasons for skipping breakfast, $8.7 \%$ of study participants indicated that they did not like what was available to eat, $11.1 \%$ indicated that nothing to eat at home while $2.2 \%$ were not hunger in morning and $8.2 \%$ did not have enough time to eat breakfast. Study done on Australian adolescents showed that the reasons adolescents give for skipping breakfast were that they were not hungry or do not have enough time to consume breakfast [26]. 
Independent sample t-test analysis showed that there were significant differences of cognitive test scores between regular and irregular breakfast eaters. [3] Assessed the effects of breakfast on cognitive function reported that skipping breakfast can have adverse effects on cognitive performance of school aged children. Investigated the effects of breakfast on children's cognitive performance had reported that study subject's cognitive performance was enhanced after eating breakfast as compared to omitting breakfast. A study done in rural Peru showed that a school breakfast program had a significant and positive effect on short term memory, arithmetic and reading comprehension [27].

Other study done in Indian children reported significant association between regular breakfast consumption patterns and immediate recall memory test as well as letter cancellation test (attention-concentration) [28]. Studies had reported that regular breakfast eaters had shown to have improved short-term memory function and increased alertness [14 and 29] and adolescents who were not consuming-breakfast had a decline in performance on verbal fluency test [10; 30 and 31]. Similarly, other study showed that children who ate breakfast regularly demonstrated improved problem-solving ability, short-term memory, attention, and episodic memory in comparison to those who did not eat breakfast, as well as better cognitive performance than breakfast skippers [32].

Multivariate linear regression analysis shows that regular breakfast eating habit, sex of study subject and education of mother were significantly $(\mathrm{P}<0.001)$ associated with Sequential scale (short term memory) explaining 13.5 percent variation. Regular breakfast habit and education of mother, height for age and body mass index for age were significantly $(\mathrm{P}<0.001)$ associated with Simultaneous scale explaining 15 percent variation.

One study conducted in Indian adolescents reported significant association between family type, regular breakfast pattern, height-for-age and science marks [33]. The same study reported significant association between education of mother, regular breakfast patterns and English mark of children's. [34], assessed the effects of breakfast on cognitive performance reported that skipping breakfast can have adverse effects on cognitive performance of school aged children. Other experimental study which had tested the effects of breakfast on memory and mood found that consuming breakfast regularly resulted in better scores on different types of memory tests which were conducted among university students in Wales [35]. The same study reported that eating breakfast regularly improves learning and cognitive performance of the children. Studies had shown that eating breakfast regularly improves standardized test scores, problem solving tasks and memory performance among children [4 and 36]. Study done in Iraq reported that children skipping breakfast in the morning have 7.4 times more risk to have low intelligence compared to those who had take breakfast every day and there is strong relationship between breakfast eating habits and intelligence quotient of children [37]. Similar study reported that the adolescents who were not consuming-breakfast had a decline in performance on verbal fluency test [8, 31 and 38].

Several studies showed that missing breakfast detrimentally affects children's cognitive function, like problem solving and short-term memory; attention and episodic memory [39]. Conversely, when children consumed breakfast, performance is enhanced on measures of vigilance attention, arithmetic, problem solving tasks, and logical reasoning [40].

The possible explanation could be the gradual decline of insulin and glucose levels could cause a stress response in children, which interferes with different aspects of cognitive function, such as attention and working memory [6]. [41] Suggested that skipping breakfast can pose serious problems for a children daily nutritional intake. The importance of micronutrient such as iron and vitamin B-12 are significant deficiencies of micronutrients had shown an impact on children's cognitive development. Alternatively, breakfast skippers run the risk of becoming malnourished which has been linked to delayed cognitive development [42]. Children who skip breakfast are at an increased nutritional risk due to the fact that the nutrients that were not consumed during breakfast are not usually replaced at later meals. Specific nutrients that breakfast skippers are up to two thirds deficient of the RDA are vitamins A, B6, and D, calcium, magnesium, riboflavin, folacin, zinc, phosphorus, and iron [43].

Adolescent's anthropometric status was also an important factor that affected their cognitive performance. Adolescents who were stunted (HAZ $<-2 \mathrm{SD}$ ) and underweight (BAZ < -2SD) had lower mean cognitive tests scores than who were normal. The Simultaneous scale which measures perceiving, storing, manipulating and thinking with visual patterns ability was significantly lower in underweight $(\mathrm{P}<0.001)$ and stunted $(\mathrm{P}=0.006)$ adolescents. Pattern Reasoning which measures solving problems by using induction and deduction reasoning was significantly lower in stunted $(\mathrm{P}=0.005)$ than in normal adolescent.

A study done by [9], reported significant relationship between the nutritional status indicators and cognitive test scores of children. Other study done in Iraq showed that malnourished children have 11.6 times more risk to have low intelligence compared to normal ones [39]. Another study conducted in Philippines adolescents showed that mental ability of adolescents with good nutritional status was significantly higher than that of adolescents with poor nutritional status, as a whole, even when family income and mental ability were controlled [11]. Similarly, study conducted on perceptual development of adolescents in relation to nutritional status with the help of picture ambiguity test (PAT) reported that there was a significant difference in the performance of well nourished and undernourished adolescents during this test [44]. Similar study conducted on influence of malnutrition on social maturity, visual motor coordination and memory of rural school children in Varanasi district revealed that verbal performance and mean IQ score decreased with severity of malnutrition [45]. Study which compared the performance of adequately nourished adolescents to malnourished adolescents found that the malnourished adolescents differed from the adequately 
nourished adolescents on tests of phonemic fluency, design fluency, selective attention, visuospatial working memory, visuospatial functions, verbal comprehension and verbal learning, and memory [46]. The same study indicated that test scores for adequately nourished adolescents were found significant but most of the test scores for undernourished adolescents showed a delay in development of certain cognitive functions [46].

\section{Conclusion}

Present study was conducted with aim of assessing effects of breakfast eating patterns, anthropometric status and cognitive function among early adolescents. Adolescents are the future and backbone of any nation. Therefore their health issues need special attention. Factors influencing breakfast eating patterns in the study area were nothing to eat at home, availability, lack of interest to eat in the morning, lack of time and not hunger. Among the breakfast skippers, majority of them were from poor family.

The findings of the present study are those adolescents who skip breakfast had low cognitive performance in the form of low scores in had movement, number recall, rover and pattern reasoning and combined sequential scale which measures short term memory and simultaneous scale which measures long term memory than regular breakfast consumer comparers. Breakfast eating patterns, maternal education, father occupation, and sex of study participants may have larger effect on cognitive development of adolescents. Adolescent's cognitive function was related to anthropometric status. Adolescents who were stunted and underweight had lower cognitive test scores compared to those who were normal. Anthropometric status was significant predictor of cognitive function of adolescents in the study area.

The results also show that breakfast skipping, anthropometric status and cognitive function are related. Significant relationship was observed between anthropometric status, breakfast eating patterns and cognitive function. Consumption or skipping breakfast and anthropometric status had beneficial influence on short term Sequential memory (taking in, holding and using information within a few seconds), Simultaneous (visual processing) and Pattern Reasoning (solving problems by using induction and deduction reasoning). Healthy eating is essential for adolescents to achieve their full academic potential, mental growth and lifelong health and well being. This finding indicates the need to implement intervention programs to reduce breakfast skipping problems and its consequences in the study as well as to improve nutritional status of adolescents.

The finding also gave further support to the evidence that improving maternal schooling, household and father occupation are very important for improving adolescents cognitive development. Breakfast eating patterns, maternal education, father occupation and sex of study participants may have larger effect on cognitive development of adolescents.

\section{Recommendations}

Breakfast eating pattern is important factors for optimal cognitive development thus more attention should be given to the regular consumption of breakfast, through implementing school breakfast program, providing nutritional education, and other health promotion activities. Nutrition education should attempt to educate adolescents, parents, teachers and school community about the importance of regular habits of eating breakfast because majority of adolescents spend their time in the school. Anthropometric status is also important factors for optimal cognitive development thus interventions that improve adolescents nutritional status should be undertaken and ensure that investments made for improving education are worthwhile.

Further studies recommended looking into both long-term and short-term effects of skipping breakfast on cognitive performance and the relationship between breakfast eating patterns (including quality and quantity of food) and cognitive function in Ethiopian adolescents.

\section{Acknowledgements}

This study was funded by NORAD project. The author would like to express their gratitude for the financial support. The authors have no conflicts of interest. They would also like to thank Dr. Samson G/medhin and Dr. Dejene Hailu for their valuable comments and Dr. Alemtsehay Bogale for her help in providing training on cognitive tests score. Finally, their appreciation goes to those adolescents and their parents who shared their time during the data collection period.

\section{References}

[1] Emery P. W. Metabolic changes in malnutrition. Eye. No. 19: 2005; pp. 1029-1034.

[2] T. Nicklas, C. Reger, L. Myers, and C. O'Neil, Breakfast consumption with and without vitamin-mineral supplement use favorably impacts daily nutrient intake of ninth-grade students. Journal of Adolescent Health; 27: 2000; pp. 314-321.

[3] F. Bellisle, Effects of diet on behavior and cognition in children. British Journal of Nutrition, suppl. No. 2: 2004; pp. 227-232.

[4] G. C. Rampersaud, M. A. Pereira, B. L. Girard, J. Adams and J. D. Metzl. Breakfast habits, nutritional status, body weight, and academic performance in children and adolescents. J. Am. Diet Assoc. 2005; 105(5): 743-749.

[5] E. Pollitt, Does breakfast make a difference in school? Child Nutrition Health Campaign; No. 10: 1995; pp. 1134-1135.

[6] R. Mathews, Importance of breakfast to cognitive Statement on the Link between Nutrition and Cognitive Development in Children. Medford, MA: Tufts University, School of Nutrition; 1996. Unpublished.

[7] E. Pollitt, R. Leibel and D. Greenfield, Brief fasting, stress, and cognition in children. American Journal of Clinical Nutrition; No. 34: 1991; pp. 1526-1533. 
[8] Simeon D. T. School feeding in Jamaica: A review of its evaluation. American Journal of Clinical Nutrition, No. 67: 1998; pp. 790-4.

[9] E. Pollit, Malnutrition and infection in the classroom. Summary and Conclusions. Food Nutrition Bulletin, 1990; 12: 3.

[10] D. T. Jamison, Child Malnutrition \& School Performance in China. J. Develop. Econ. No. 2: 1986; pp. 299-309.

[11] C. Florencio. Report to UNESCO on school health and nutrition problems and programs in the Philippines. 1990; Paris: UNESCO.

[12] H. T. Chugani, A critical period of brain development: Studies of cerebral glucose utilization with PET. Preventive Medicine, No. 27: 1998; pp. 184-188.

[13] A. Hoyland, L. Dye and C. L. Lawton, A systematic review of the effect of breakfast on the cognitive performance of children and adolescents. Nutrition Research Reviews; 22: 2009; pp. 220-243.

[14] G. C. Rampersaud, Benefits of breakfast for children and adolescents: Update and recommendations for practitioners. American Journal of Lifestyle Medicine; No. 3: 2009; pp. 86-103.

[15] F. Faul, E. Erdfelder, A. G. Lang and A. Buchner, G*Power 3: A flexible statistical power analysis program for the social, behavioral, and biomedical sciences. Behavior Research Meth. 2007.

[16] WHO, the management of Malnutrition in Major Emergencies. Geneva; WHO: 2000; pp. 210-234.

[17] CSA and ORC Macro, EDHS, 2012. Addis Ababa, Ethiopia and Calverton, Maryland, USA: ESA and ORC Macro: 2012.

[18] R. S. Gibson, Principles of Nutritional Assessment. 2ed. New York: Oxford University Press: 2005.

[19] M. de Onis, A. W. Onyango, E., A. Borghi Siyam, C. Nishida J. Siekmann. Development of a WHO growth reference for school-aged children and adolescents. Bull World Health Organ, No. 85: 2007; pp. 660-667.

[20] A. Kaufman and N. Kaufman; Kaufaman assessment battery for children: AGS Publishing. Circle Pines, MN: 2004; PP. $1-224$.

[21] N. S., S. Gajre, N. Fernandez, Balkrishna and S. Vazir, Breakfast Eating Habit and its Influence on Attention-concentration, Immediate Memory and School Achievement. Indian Pediatrics, Vol. 45: 2008; pp. 824-828.

[22] C. S. Y. Tereza, A. H Lap, Y. U. Tse, GnatiusTak-sun and G. Sian Children' Perceptions of Parental Attitude Affecting Breakfast Skipping in Primary Sixth-Grade Students. J. School Health, Vol. 78, Am. School Health Assoc.: 2008; pp. 203- 208.

[23] T. Nicklas, C. O'Neil and L. Myers, The importance of breakfast consumption to nutrition of children, adolescents, and young adults. Nutrition Today No. 39; Vol. 1: 2004; pp. 30-39.

[24] M. Murata, Secular trends in growth and changes in eating patterns of Japanese children. American Journal of Clinical Nutrition, Vol. 72: 2000; pp. 1379-1383.

[25] S. Basrur, Child nutrition programs in Toronto to the Toronto Board of Health; 1998.
[26] M. Shaw, Adolescent breakfast skipping: an Australian Study. Adolescence, No. 33; Vol. 132: 1998; pp. 851-861.

[27] S. Cueto and M. Chinen, Educational impact of a school breakfast programme in rural Peru. Int. J. Educ. Dev. , Vol. 28: 2008; pp. 132-148.

[28] N. S., S. Gajre, N. Fernandez, Balkrishna and S. Vazir, Breakfast Eating Habit and its Influence on Attention-concentration, Immediate Memory and School Achievement. Indian Pediatrics, Vol. 45: 2008; pp. 824-828.

[29] M. K. Widenhorn, K. Hille, J. Klenk and U. Weiland, Influence of having Breakfast on Cognitive Performance and Mood in 13- to 20-Year-Old High School Students: Results of a Crossover Trial. Pediatrics, Vol. 122: 2008; pp. 279-284.

[30] M. S. Grantham, M. S. Chang and S. P. Walker, Evaluation of school feeding programs: Some Jamaican examples. American Journal of Clinical Nutrition. Vol. 67:1998; 142-184.

[31] E. Pollitt, S. Cueto and E. R. Jacoby, Fasting and cognition in well- and undernourished schoolchildren: a review of three experimental studies, American Journal of Clinical Nutrition, 67(suppl): 1998; pp. 779-784.

[32] L. Dye, A. Lluch and J. E. Blundell, Macronutrients and mental performance. Nutrition No. 16. Vol. 10: 2000; pp. 1021-34.

[33] N. S. Gajre, S. Fernandez, N. Balkrishna \& S. Vazir, Breakfast Eating Habit and its Influence on Attention-concentration, Immediate Memory and School Achievement. Indian Pediatrics, No. 45: 2008; pp. 824-828.

[34] F. Bellisle, Effects of diet on behavior and cognition in children. British Journal of Nutrition, suppl. No. 2: 2004; pp. 227-232.

[35] D. Benton \& P. Y. Parker, Breakfast, blood glucose, and cognition, American Journal of Clinical Nutrition, 67(suppl): 1998; pp. 772-778.

[36] K. Alaimo, C. M. Olson \& E. A. J. Frongillo, Food insuffciency and American school-aged children's cognitive, academic and psychosocial development. Pediatrics, No. 108; Vol. 1:2001; pp. 44-53.

[37] F. G. Hasanain, M. Zaleha, S. Isa, A. Aljunid, T. Mohd \& A. Mohammed, Nutritional Status, Nutritional Habit and Breakfast Intake in Relation to IQ among Primary School Children in Baghdad City, Iraq. Pak. J. Nutr. No. 11, Vol. 4: 2012; pp. 379-382.

[38] M. Grantham. , S. M., S. Chang \& S. P. Walker, Evaluation of school feeding programs: Some Jamaican examples. American Journal of Clinical Nutrition. No. 67: 1998; pp. 142-184.

[39] K. A. Wesnes, C. Pincock, D. Richardson, G. Helm. \& S. Hails, Breakfast reduces declines in attention and memory over the morning in school children. Appetite, No. 41, Vol. 3: 2003; $329-31$.

[40] A. M. Marquez., R. Sutil de Naranjo, C. E. Rivas de Yepez. , M. Rincon Silva, M. Torres, R. D. Yepez et al., Influence of breakfast on cognitive functions of children from an urban area in Valencia, Venezuela. Arch Latinoam Nutr. No. 51, Vol. 1: 2001; pp. 57- 63 .

[41] S. Malone, Improving the quality of student's dietary intake in the school setting. The Journal of School Nursing, No. 21, Vol. 2: 2005; pp. 70-76. 
[42] C. Bayerl \& J. Stang, Position of the American Dietetic As sociation: Child and Adolescent food and nutrition programs. Journal of the American Dietetic Association, No. 103, Vol. 7: 2003; pp. 887-893.

[43] T. Nicklas, C. O'Neil \& L. Myers, The importance of breakfast consumption to nutrition of children, adolescents, and young adults. Nutrition Today, No. 39, Vol. 1: 2004; pp. 30-39. New Zealand Red Cross. Red Cross Breakfast in Schools: National Evaluation Report. Wellington: New Zealand Red Cross.

[44] S. K. Upadhyaya., T. B. Singh, S. Alka \& B. D. Bhatia
Perceptual development in relation to nutritional status. Indian J. Pediatric, No. 68, Vol. 4: 2001; pp. 327-332.

[45] S. K. Upadyaya., D. K. Agarwal \& K. N. Agarwal., Influence of malnutrition on social maturity, visual motor co-ordination and memory on rural school children. Indian J. Med. Res., No. 90: 1989; pp. 320-327.

[46] B. Karim, S. Rao \& B. Chandramouli, Cognitive development in children with chronic protein energy malnutrition. Behavioral and Brain Functions, No. 4, Vol. 31, 2008. doi: 10. 1186/1744, 9081-4 31. 